\title{
New Concept for the Design of Flexible Pavement at Critical Highway Sections
}

\author{
A. El-Desouky* and G. EL-Sheakhy†
}

\begin{abstract}
The design procedure of flexible pavement to be completely rational in nature, consideration should be given to all forces acting on pavement through the vehicle's tire. Although the horizontal forces (HF) on the pavements are of significant values, all pavement design methods do not take the actions of these forces on the pavement system into consideration. This may appear to be unrealistic load condition. Previous studies concluded that horizontal forces have significant effect on the response of flexible pavements. The main objective of this research is to recommend/quantify solutions to eliminate the effect of these forces on the response of flexible pavements. To achieve this objective theoretical analysis, using finite element technique, was performed to investigate the response of different flexible pavement sections under various wheel loads. Linear analysis was conducted using the computer program ANSYS 12.1. The basic measuring parameters of flexible pavement in this study were; the maximum surface deflection (SD), the maximum horizontal tensile strain at the bottom of asphalt concrete layer $\left(\varepsilon_{t}\right)$ and the maximum compressive strain at the top of subgrade $\left(\varepsilon_{c}\right)$. A total of 643 cases were studied to investigate the effect of HF on the behavior of asphalt pavements. Based on the response of asphalt pavement under HF, recommended pavement sections were adopted to eliminate the effect of HF. Reduction of the effect of HF on the flexible pavement response may achieved by increasing the AC layer thickness $\left(\mathrm{h}_{1}\right)$ followed by the asphalt concrete layer modulus $\left(\mathrm{E}_{1}\right)$ or by increasing the base layer modulus $\left(\mathrm{E}_{2}\right)$.
\end{abstract}

Keywords: flexible pavement, horizontal forces, design, critical sections

\section{Introduction}

There are three forces acting on the tire from the pavement. Tractive force (or longitudinal force) $F_{x}$ is the component in the $\mathrm{X}$ direction of the resultant force exerted on the tire by the road. Lateral force $F_{y}$ is the component in the $Y$ direction, and normal force $F_{z}$ is the component in the $\mathrm{Z}$ direction (vertical load, VL). Although horizontal forces are of significant values, most of the design methods for flexible pavement do not take the effect of horizontal forces into consideration. They used only the effect of vertical wheel load or axle load [1].

In (1999) Khedr et al. studied the effect of HF on the performance of flexible pavements. Although they suggested to increase the thickness of surface layer and to enhance the properties of asphalt concrete (AC) layer to maintain high modulus, they did not quantify the required amount of increase of both $\mathrm{AC}$ thicknesses and modulus. In addition, they did not study the effect of base layer thickness and modulus [2]. El-Desouky et al. (1999) found that

\footnotetext{
* Egyptian Armed Forces, Egypt; aeldesouky71@yahoo.com

$\dagger$ Libyan Armed Forces
} 
AC layer modulus $\left(E_{1}\right)$ has significant effect on the flexible pavement response and the predicted pavement life. There was a so-called critical modulus $\mathrm{E}_{1}$ at which $\varepsilon_{\mathrm{t}}$ is a maximum. The critical $E_{1}$ values decreased as $h_{1}$ increased under various wheel loads. For $E_{1}$ values below the critical values there was a significant effect horizontal force (HF) on flexible pavement response. On other words, the effect of HF decreased with increasing $E_{1}$ [3]. Similar findings were obtained after studying the response of flexible pavements under trucked vehicle loads and aircraft loads [4, 5]. El-Desouky and El-Shikhy (2014) studied the effect of base thickness and base modulus on the response of flexible pavement under various wheel loads. They found that the effect of horizontal forces on flexible pavement response decreases with; increasing asphalt concrete layer thickness $\left(\mathrm{h}_{1}\right)$, increasing base layer modulus $\left(\mathrm{E}_{2}\right)$ and/or increasing asphalt concrete layer modulus $\left(\mathrm{E}_{1}\right)[6]$.

The main objective of this paper is to eliminate the effects of horizontal forces, if exist at critical highway sections, on the response of flexible pavements through quantifying the required increase in different layers thickness and/or modulus. To achieve this objective, theoretical analysis, using finite element technique, was performed to investigate the response of different flexible pavement sections under various wheel loading schemes. Linear analysis was performed using computer program (ANSYS 12.1) [7]. The basic measuring parameters of flexible pavement in this thesis are, the maximum surface deflection (SD), the maximum horizontal tensile strain at the bottom of asphalt concrete layer $\left(\varepsilon_{t}\right)$ and the maximum compressive strain at the top of subgrade $\left(\varepsilon_{\mathrm{c}}\right)$. The pavement structure was composed of three layers; asphalt surface, untreated base, and subgrade. The studied variables were HF values, layers thickness $\left(h_{1}, h_{2}\right)$ and layers modulus $\left(E_{1}, E_{2}\right)$. Results of a previous study [6] were used in this research where HF in addition to VL were applied to the pavement structural sections referred here as original sections. New pavement sections, if required, were studied and compared to the original sections to determine recommended pavement sections that could eliminate the effect of HF.

\section{Finite Element Modeling}

As mentioned before, flexible pavement structure was assumed to have three layers. The interface between any two consecutive layers was assumed to be perfectly bonded as recommended by the asphalt institute [8]. A set of boundary conditions was defined for the model to provide stability to the structural system. The analysis model was established with a fixed boundary at the bottom and roller supports on sides. This conforms to the assumptions of Uddin et al. [9]. In this study, a single wheel load of $40 \mathrm{kN}$ (9000 lb) was applied over a circular contact area of $30 \mathrm{~cm}$ diameter. The tire pavement contact pressure was 80 psi (5.7 $\mathrm{kg} / \mathrm{cm}^{2}$ ). This represented the vertical wheel load VL. The analysis was focused on the effect of horizontal force (HF) in additional to vertical wheel load (VL) on the maximum surface deflection, the maximum horizontal tensile strain $\left(\varepsilon_{t}\right)$ at the bottom of the AC layer and the maximum vertical compressive strain $\left(\varepsilon_{\mathrm{c}}\right)$ at the top of subgrade. Table 1 shows the layers properties data [6].

\section{Effect of Horizontal Forces on the Response of Flexible Pavements}

The Results showed that, the maximum horizontal tensile strain at bottom of the AC layer $\left(\varepsilon_{t}\right)$ is changed significantly when horizontal forces were applied to the pavement structure. In addition, it was noticed that the compressive strain at the top of subgrade layer $\left(\varepsilon_{\mathrm{c}}\right)$ did not change under effect of all horizontal forces values. Detailed results and analysis of results can be found elsewhere [6]. 
Table 1. Layer Properties Data [6]

\begin{tabular}{c|c|c|c}
\hline Layer & Thickness $(\mathrm{cm})$ & Modulus $(\mathrm{MPa})$ & Poisson's ratio \\
\hline $\mathrm{AC}$ & $5 / 10 / 15 / 20$ & $750-2250$ & 0.35 \\
Untreated base & $20 / 35$ & $100 / 250$ & 0.30 \\
Subgrade & $80 / 90 / 100$ & 50 & 0.40 \\
\hline
\end{tabular}

Based on these results it is planned to study how to control the maximum horizontal tensile strain $\left(\varepsilon_{t}\right)$ under application of HF. The HF value of $0.6 \mathrm{VL}$ had a significant effect on maximum horizontal tensile strain $\left(\varepsilon_{\mathrm{t}}\right)$ for all studied cases. For $\mathrm{h}_{1}=5 \mathrm{~cm}$ only, all values of $\mathrm{HF}$ had significant effects on $\varepsilon_{t}$. As $\mathrm{h}_{1}, \mathrm{~h}_{2}, \mathrm{E}_{1}$, and $\mathrm{E}_{2}$ increased the effect of $\mathrm{HF}$ on $\varepsilon_{\mathrm{t}}$ decreased. The following paragraphs introduce the concept of eliminating the effect of $\mathrm{HF}$ on the horizontal tensile strain at the bottom of $\mathrm{AC}$ layer for $\mathrm{HF}=0.6 \mathrm{VL}$.

\section{Eliminating the Effect of Horizontal Forces}

This part of research concerns with the concepts of eliminating the effect of horizontal force on the response of the flexible pavements. Fig. 1 - (a) shows the relationship between $\varepsilon_{\mathrm{t}}$ and $\mathrm{E}_{1}$ for $\mathrm{h}_{1}=5 \mathrm{~cm}$ and $\mathrm{h}_{2}=20 \mathrm{~cm}$ for both $\mathrm{E}_{2}=100 \mathrm{MPa}$ and $\mathrm{E}_{2}=250 \mathrm{MPa}$ under VL only (plotted in dotted lines). On the same figure, all cases, where 0.6 VL was applied as HF to the pavement structure, were plotted. The figure illustrates some close curves to the curve of VL only where $\mathrm{h}_{1}=5 \mathrm{~cm}, \mathrm{~h}_{2}=20 \mathrm{~cm}$. Fig. $1-$ (b) presents the solution to eliminate the effect of $\mathrm{HF}$ on $\varepsilon_{\mathrm{t}}$. The figure shows that for $\mathrm{E}_{2}=100 \mathrm{MPa}$ on normal road sections, $\mathrm{h}_{1}=5 \mathrm{~cm}$, and $\mathrm{h}_{2}$ $=20 \mathrm{~cm}$ might be used. While at critical sections where HF exists, there are two choices. The first one is to increase $h_{1}$ to $10 \mathrm{~cm}$ and use surface layer of modulus $E_{1} \geq 1250 \mathrm{MPa}$. The second recommended solution is to increase $h_{1}$ to $15 \mathrm{~cm}$. For $E_{2}=250 \mathrm{MPa}, \mathrm{h}_{1}=15 \mathrm{~cm}$ and $\mathrm{h}_{2}$ $=35 \mathrm{~cm}$ might be used in case of HF existence instead of $5 \mathrm{~cm}$ and $20 \mathrm{~cm}$ respectively.

Similarly, when normal road section has $h_{1}=10 \mathrm{~cm}$ and $h_{2}=20 \mathrm{~cm}$ as shown in Fig. 2, it is seen that the closest curve to the curve of VL only for $\mathrm{h}_{1}=10 \mathrm{~cm}, \mathrm{~h}_{2}=20 \mathrm{~cm}$ and $\mathrm{E}_{2}=100$ $\mathrm{MPa}$ is the curve of $\mathrm{h}_{1}=10 \mathrm{~cm}$ and $\mathrm{h}_{2}=35$ when HF of $0.6 \mathrm{VL}$ exists, i.e., $\mathrm{h}_{2}$ should be increased from $20 \mathrm{~cm}$ to $35 \mathrm{~cm}$ to eliminate the effect of HF. This solution is valid only for $\mathrm{E}_{1}$ values $\geq 1750 \mathrm{MPa}$. Another solution is to use better base course of modulus $\mathrm{E}_{2}=125 \mathrm{MPa}$. Also, when $\mathrm{E}_{2}=250 \mathrm{MPa}$, the best solution to eliminate the effect of $\mathrm{HF}$ is to use $\mathrm{h}_{1}=15 \mathrm{~cm}$ and $\mathrm{h}_{2}=35 \mathrm{~cm}$ when HF exists.

For the case of $h_{1}=10 \mathrm{~cm}$ and $h_{2}=35 \mathrm{~cm}$, as shown in Fig. 3, there are some close curves to the curve of VL only. At critical section when HF exists, the normal road section where $\mathrm{h}_{1}=$ $10 \mathrm{~cm}, \mathrm{~h}_{2}=35 \mathrm{~cm}$ and $\mathrm{E}_{2}=100 \mathrm{MPa}$ might be replaced by a section of $\mathrm{h}_{1}=15 \mathrm{~cm}$ and $\mathrm{h}_{2}=$ $20 \mathrm{~cm}$. While when $\mathrm{E}_{2}=250 \mathrm{MPa}$ the recommended section consists of $\mathrm{h}_{1}=15 \mathrm{~cm}$ and $\mathrm{h}_{2}=$ $35 \mathrm{~cm}$ and modulus of AC layer should be $\geq 750 \mathrm{MPa}$ to eliminate the effect of horizontal forces on maximum horizontal tensile strain.

Next case is when normal road section has $\mathrm{h}_{1}=15 \mathrm{~cm}$ and $\mathrm{h}_{2}=20 \mathrm{~cm}$. When $\mathrm{E}_{2}=100 \mathrm{MPa}$ as shown in Fig. 4, the recommended solution for this case is to increase $h_{2}$ to $35 \mathrm{~cm}$. While when $E_{2}=250 \mathrm{~cm}$ the best solution is to use $h_{1}=15 \mathrm{~cm}, h_{2}=35 \mathrm{~cm}$ and $E_{1} \geq 750 \mathrm{MPa}$. 


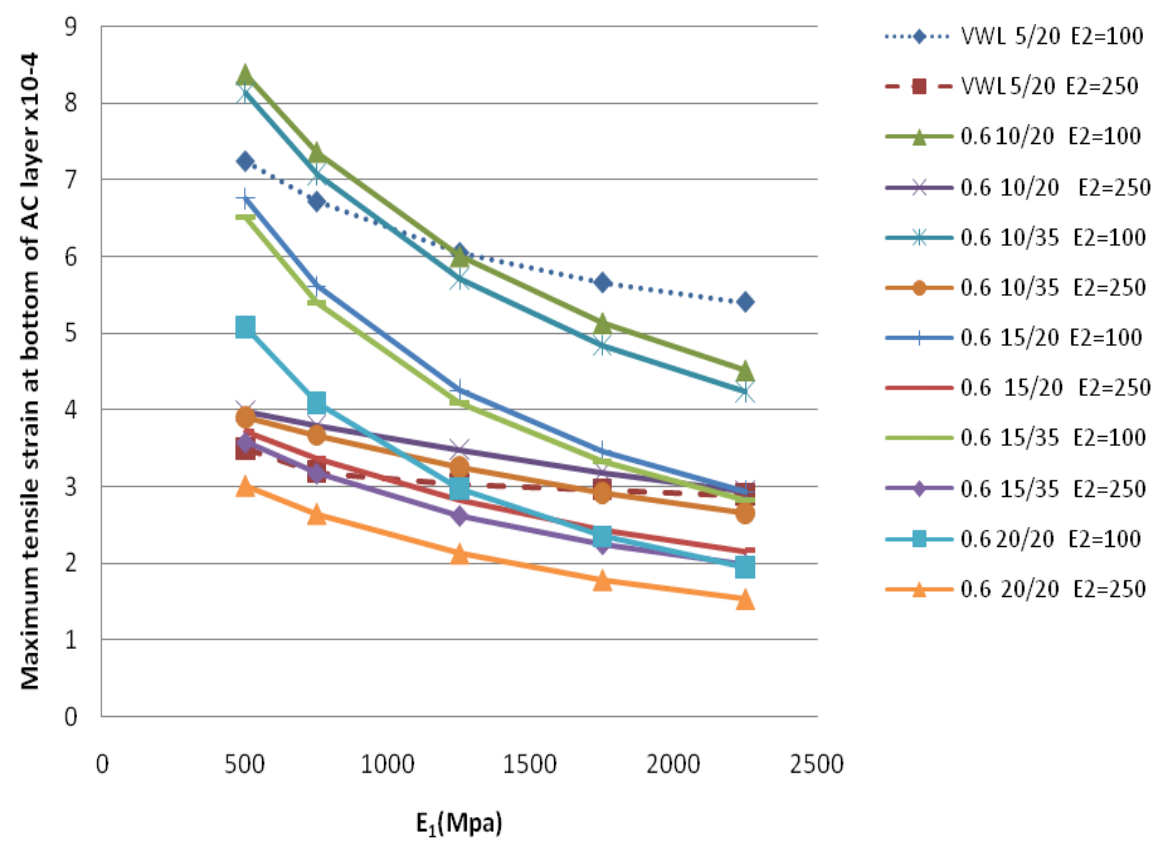

(a) Variation of $\varepsilon_{t}$ with loads and pavement sections

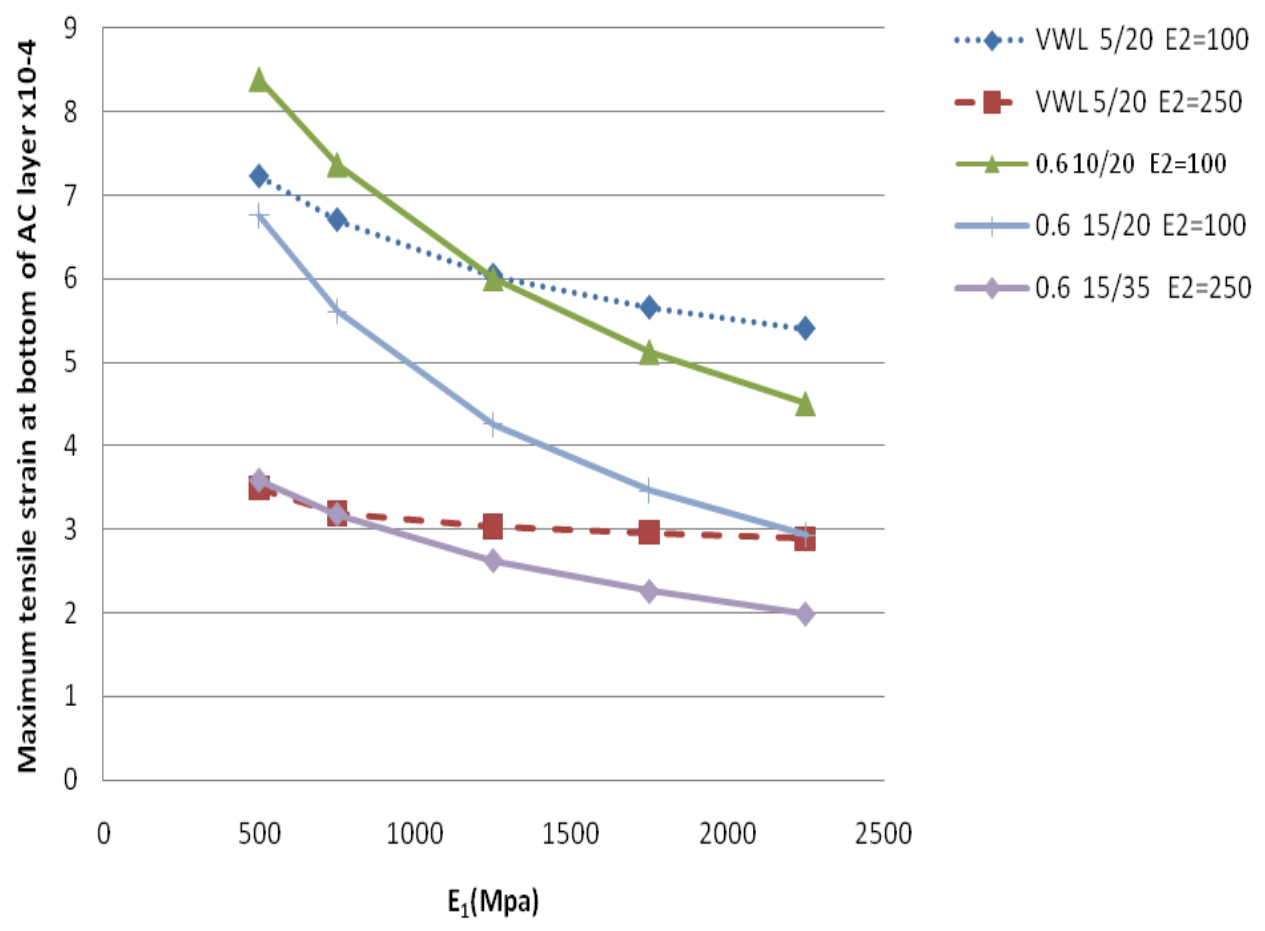

(b) Recommended solutions

Fig. 1. Elimination of the Effect of $\mathrm{HF}$ for $\mathrm{h}_{1}=5 \mathrm{~cm}$ and $\mathrm{h}_{2}=20 \mathrm{~cm}$ 

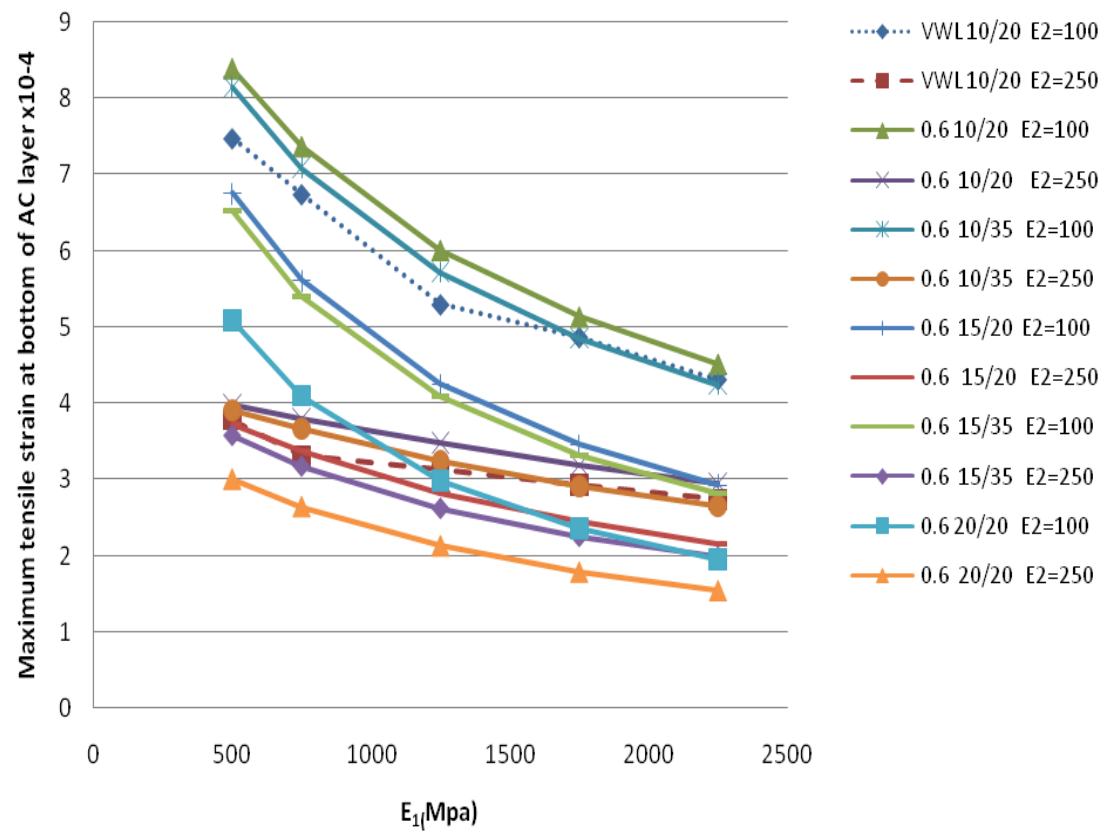

(a) Variation of $\varepsilon_{\mathrm{t}}$ with loads and pavement sections

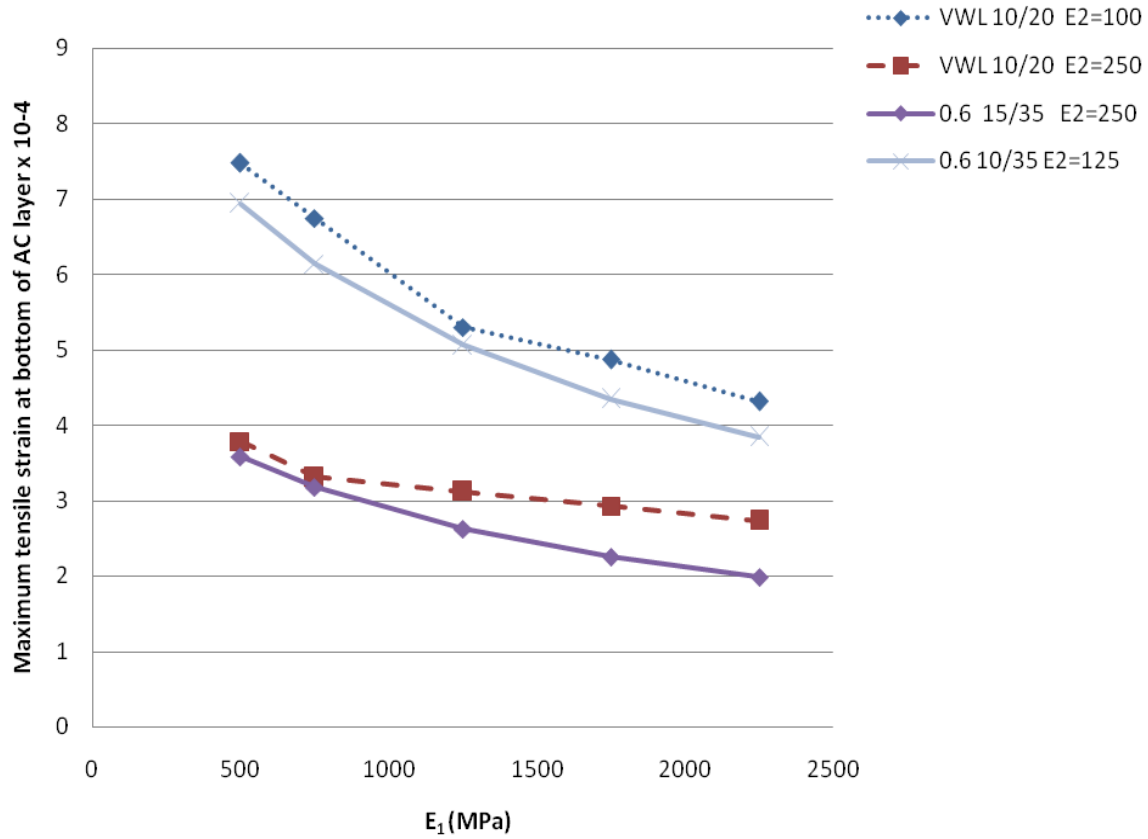

(b) Recommended solutions

Fig. 2. Elimination of the Effect of $\mathrm{HF}$ for $\mathrm{h}_{1}=10 \mathrm{~cm}$ and $\mathrm{h}_{2}=20 \mathrm{~cm}$ 

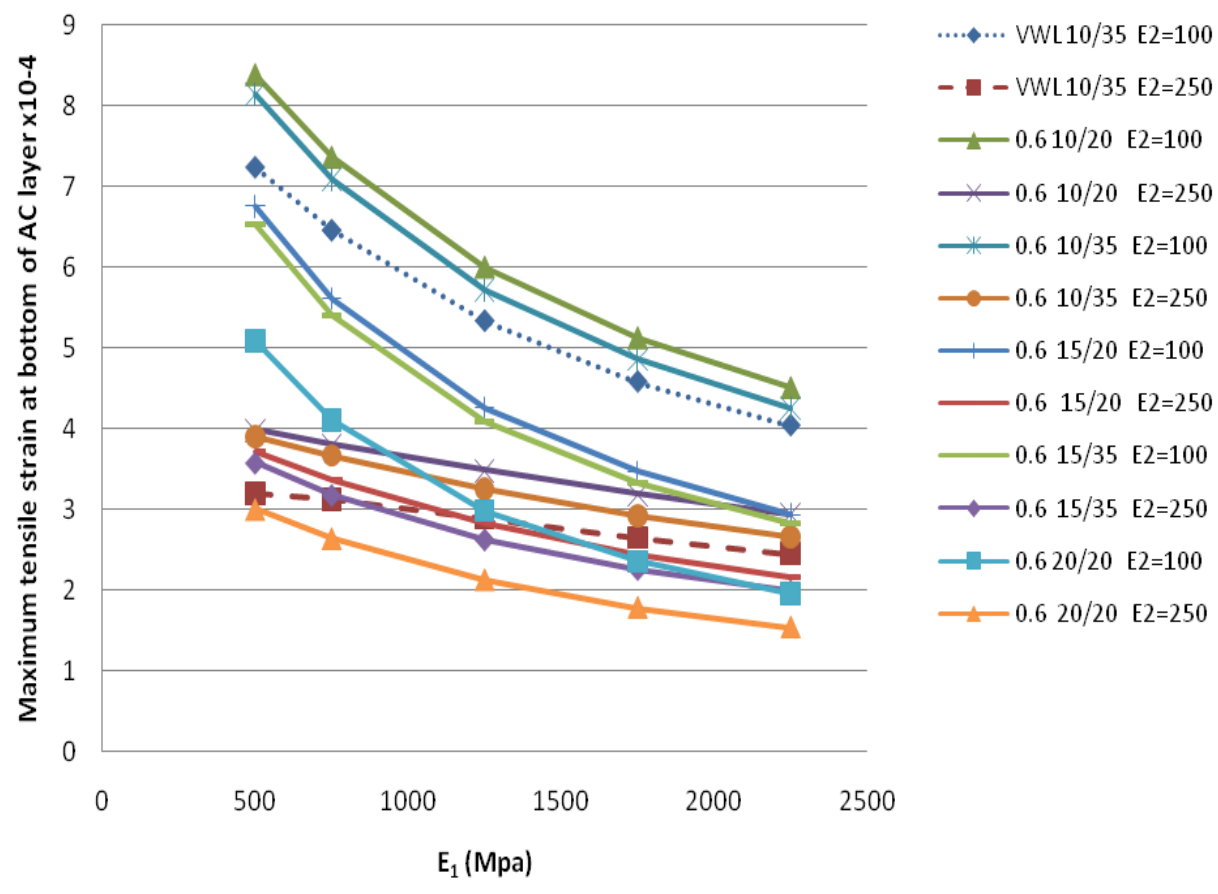

(a) Variation of $\varepsilon_{t}$ with loads and pavement sections

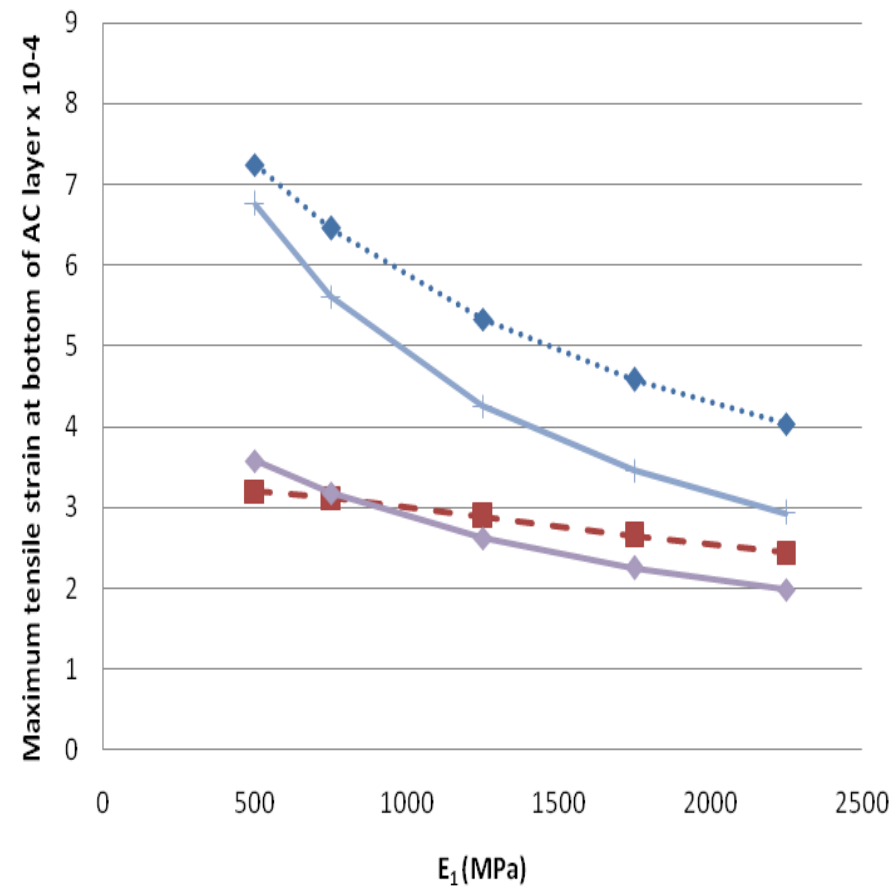

…*... VWL10/35 E2=100

- - VWL $10 / 35 \mathrm{E} 2=250$

$-0.615 / 20 \mathrm{E} 2=100$

$\longrightarrow 0.615 / 35 \quad$ E2$=250$

(b) Recommended solutions

Fig. 3. Elimination of the Effect of $\mathrm{HF}$ for $\mathrm{h}_{1}=10 \mathrm{~cm}$ and $\mathrm{h}_{2}=35 \mathrm{~cm}$ 


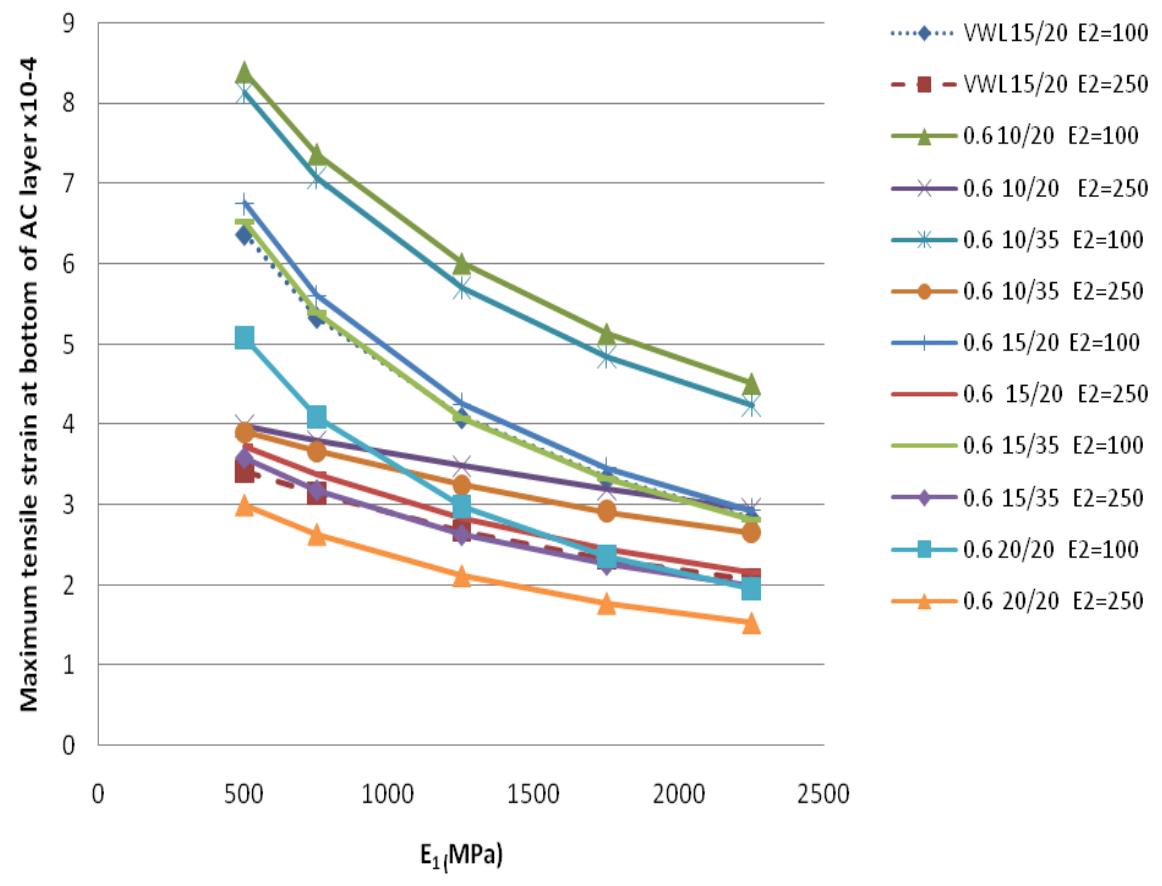

(a) Variation of $\varepsilon_{t}$ with loads and pavement sections

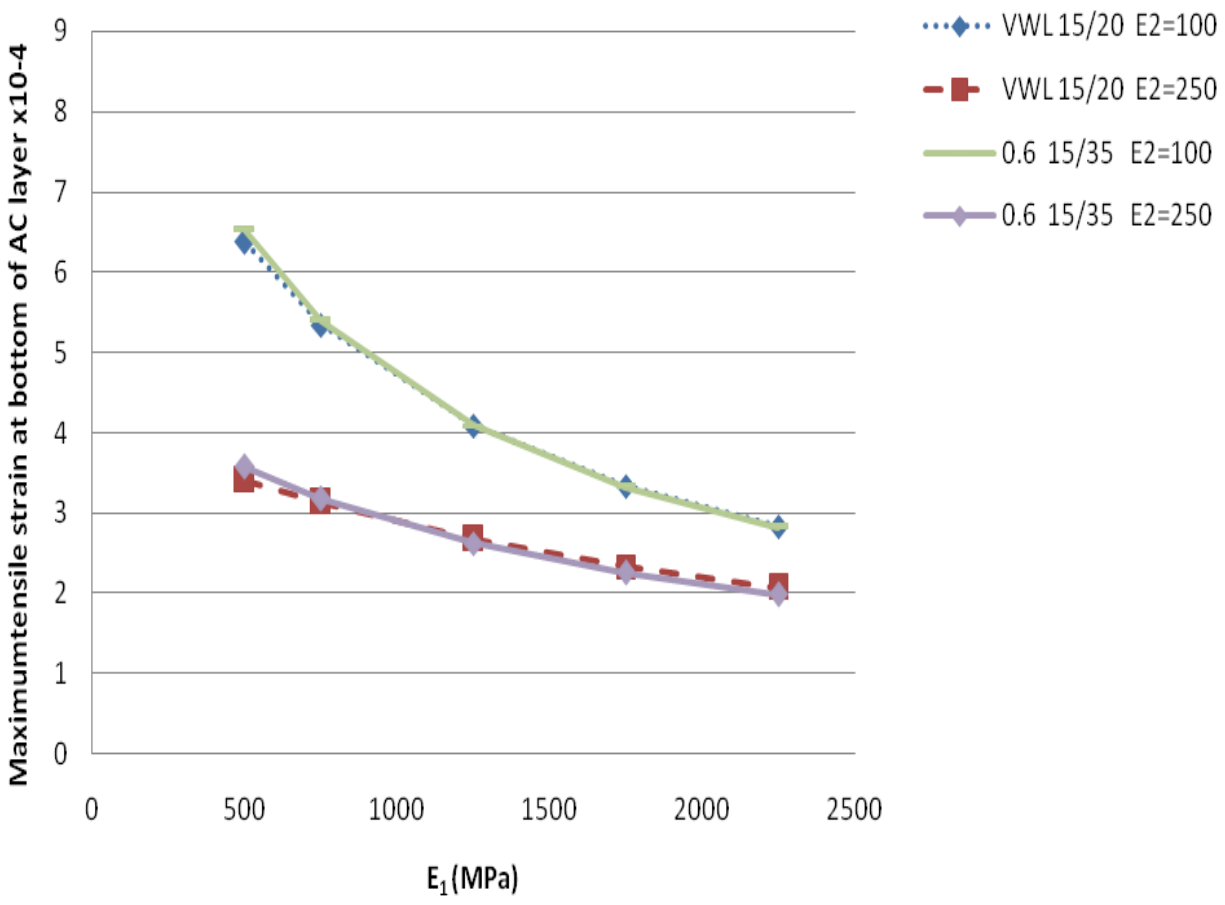

(b) Recommended solutions

Fig. 4. Elimination of the Effect of $\mathrm{HF}$ for $\mathrm{h}_{1}=15 \mathrm{~cm}$ and $\mathrm{h}_{2}=20 \mathrm{~cm}$

Fig. 5 illustrates some close curves to the curve of VL only when $\mathrm{h}_{1}=15 \mathrm{~cm}, \mathrm{~h}_{2}=35 \mathrm{~cm}$. The solution to eliminate the effect of the $\mathrm{HF}$ on $\varepsilon_{\mathrm{t}}$ when $\mathrm{E}_{2}=100 \mathrm{MPa}$ is to replace the normal road section by the recommended section of $\mathrm{h}_{1}=15 \mathrm{~cm}, \mathrm{~h}_{2}=20 \mathrm{~cm}$ and $\mathrm{E}_{2}=125 \mathrm{MPa}$. For $\mathrm{E}_{2}=250 \mathrm{MPa}$, it is recommended to use $\mathrm{h}_{1}=20 \mathrm{~cm}, \mathrm{~h}_{2}=20 \mathrm{~cm}$. The second recommended solution is to use $\mathrm{h}_{1}=20 \mathrm{~cm}, \mathrm{~h}_{2}=20 \mathrm{~cm}$ and $\mathrm{E}_{2}=200 \mathrm{MPa}$ but $\mathrm{E}_{1}$ should $\geq 750 \mathrm{MPa}$. 

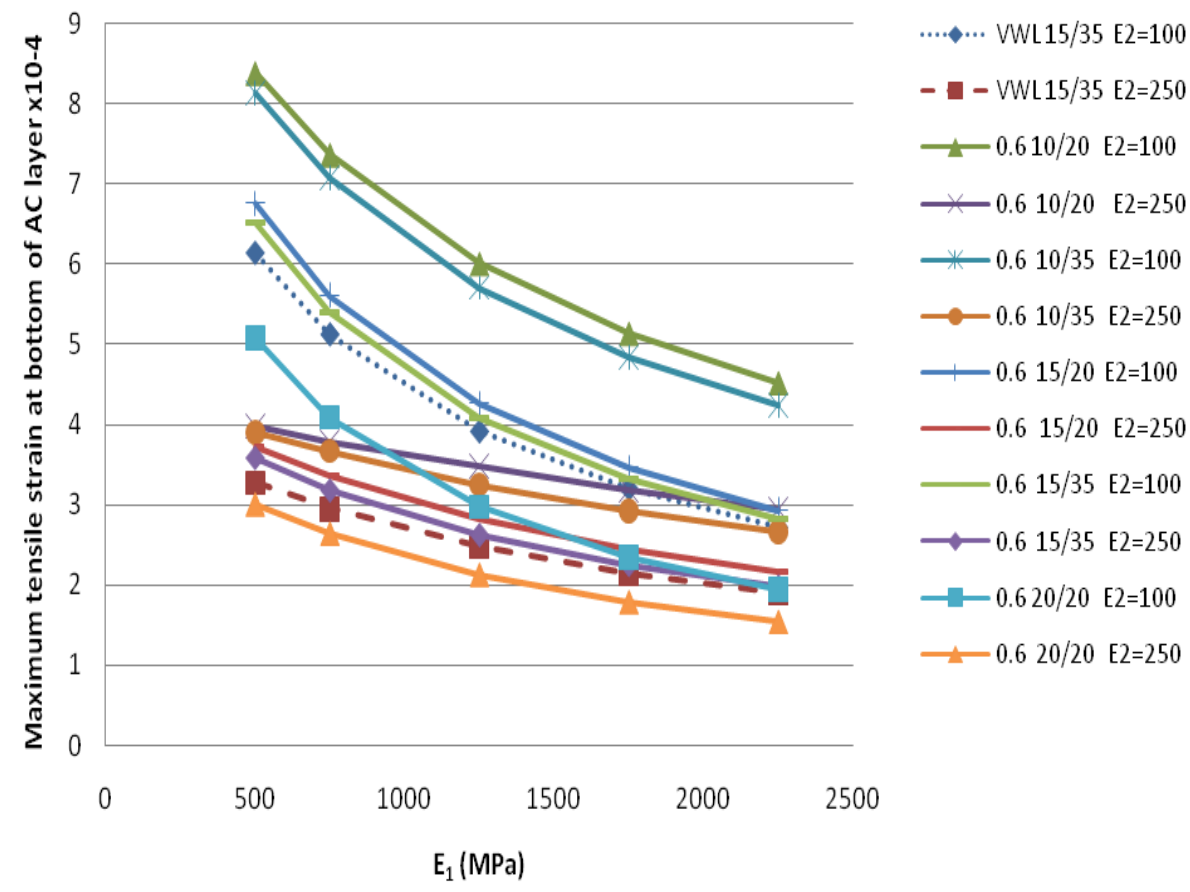

(a) Variation of $\varepsilon_{\mathrm{t}}$ with loads and pavement sections

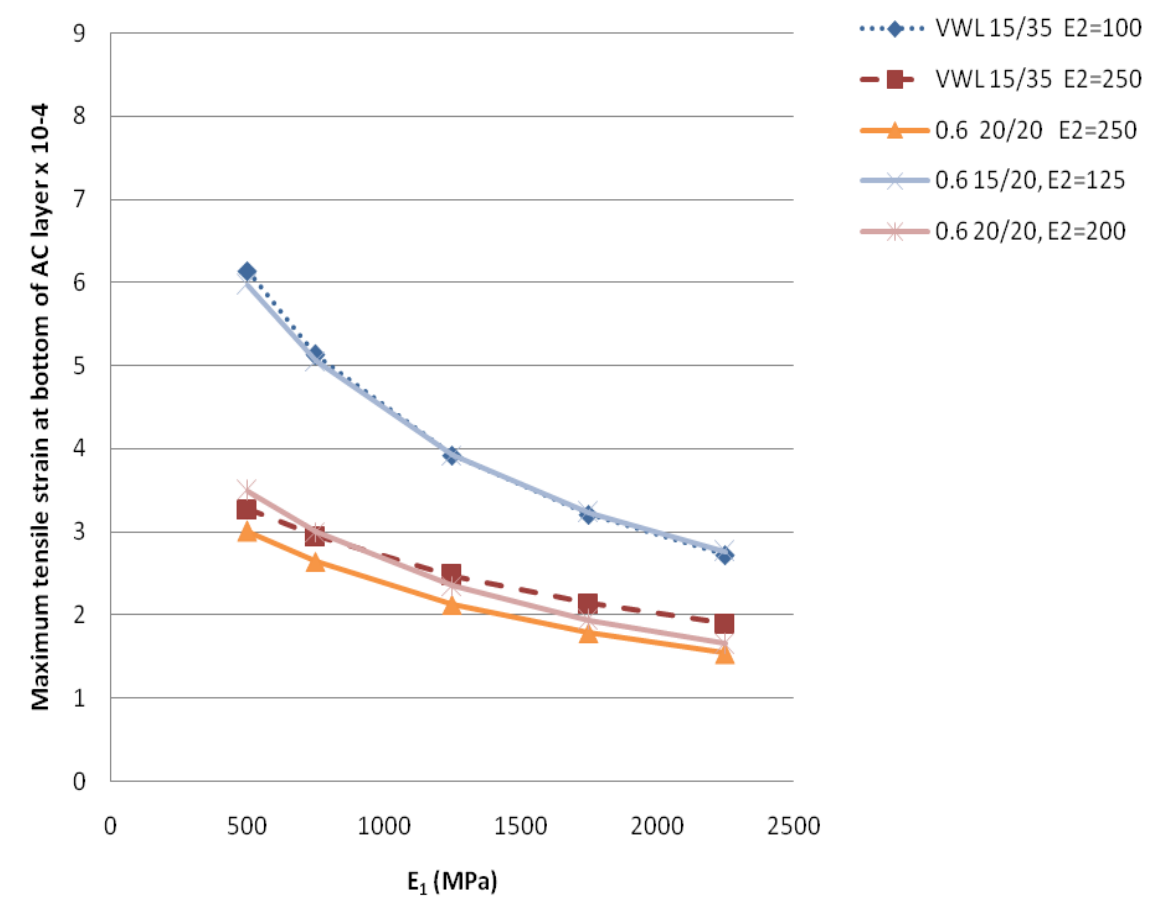

(b) Recommended solutions

Fig. 5. Elimination of the Effect of HF for $h_{1}=15 \mathrm{~cm}$ and $h_{2}=35 \mathrm{~cm}$

The last case in this study is when the normal road section has $\mathrm{h}_{1}=20 \mathrm{~cm}$ and $\mathrm{h}_{2}=20 \mathrm{~cm}$ as shown in Fig. 6. The recommended solution for this case is to increase $h_{2}$ to $30 \mathrm{~cm}$ for both $\mathrm{E}_{2}$ values of $100 \mathrm{MPa}$ and $250 \mathrm{MPa}$. Table 2 summarizes the results of the work presented in this paper. In this table, the recommended sections are introduced against original sections to eliminate the effect of HF on the response of flexible pavements at critical road sections where horizontal forces may exist. 


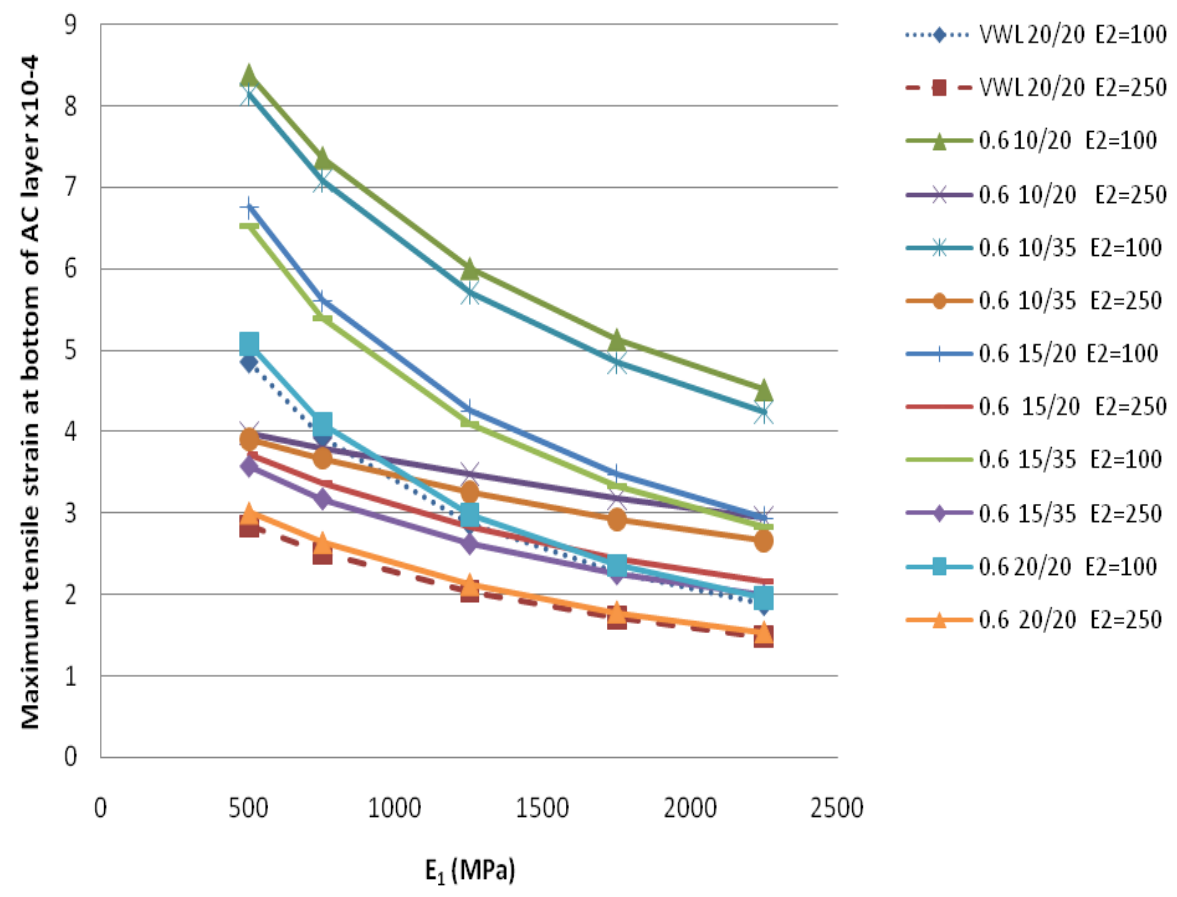

(a) Variation of $\varepsilon_{t}$ with loads and pavement sections

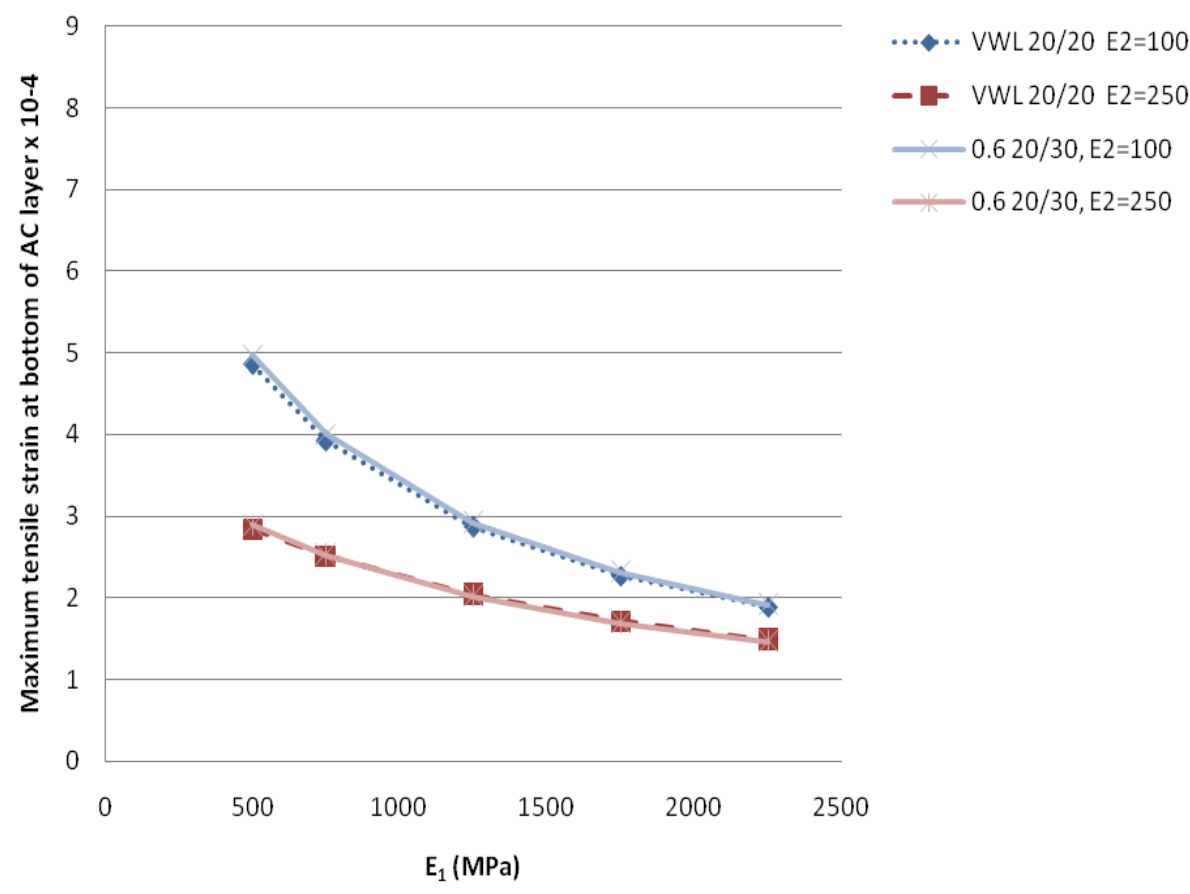

(b) Recommended solutions

Fig. 6. Elimination of the effect of $\mathrm{HF}$ for $\mathrm{h}_{1}=20 \mathrm{~cm}$ and $\mathrm{h}_{2}=20 \mathrm{~cm}$ 
Table 2. Summary of the Recommended Sections to Eliminate the Effect of HF

\begin{tabular}{|c|c|c|c|c|c|c|}
\hline \multicolumn{3}{|c|}{ Original Section } & \multicolumn{4}{|c|}{ Recommended Section } \\
\hline $\mathrm{h}_{1}$ & $\mathrm{~h}_{2}$ & $\mathrm{E}_{2}$ & $\mathrm{~h}_{1}$ & $\mathrm{~h}_{2}$ & $E_{2}$ & Notes \\
\hline \multirow{3}{*}{5} & \multirow{3}{*}{20} & 100 & 15 & 20 & 100 & \multirow{3}{*}{$\mathrm{E} 1 \geq 1250 \mathrm{MPa}$} \\
\hline & & & 10 & 20 & 100 & \\
\hline & & 250 & 15 & 35 & 250 & \\
\hline \multirow{5}{*}{10} & \multirow{3}{*}{20} & 100 & 10 & 35 & 100 & \multirow[t]{2}{*}{$\mathrm{E} 1 \geq 1750 \mathrm{MPa}$} \\
\hline & & & 10 & 35 & 125 & \\
\hline & & 250 & 15 & 35 & 250 & \\
\hline & \multirow{2}{*}{35} & 100 & 15 & 20 & 100 & \\
\hline & & 250 & 15 & 35 & 250 & $\mathrm{E} 1 \geq 750 \mathrm{MPa}$ \\
\hline \multirow{5}{*}{15} & \multirow{2}{*}{20} & 100 & 15 & 35 & 100 & \\
\hline & & 250 & 15 & 35 & 250 & $\mathrm{E} 1 \geq 750 \mathrm{MPa}$ \\
\hline & \multirow{3}{*}{35} & 100 & 15 & 20 & 125 & \\
\hline & & 250 & 20 & 20 & 250 & \\
\hline & & & 20 & 20 & 200 & $\mathrm{E} 1 \geq 750 \mathrm{MPa}$ \\
\hline \multirow{2}{*}{20} & \multirow{2}{*}{20} & 100 & 20 & 30 & 100 & \\
\hline & & 250 & 20 & 30 & 250 & \\
\hline
\end{tabular}

\section{Conclusion}

The work presented in this paper provides the corner stone and a new concept to eliminate the effects of horizontal forces, if exist, at critical sections on flexible pavement response:

1.The rational analysis quantifies the new required pavement sections and layer moduli to eliminate the effects of HF.

2.The key to eliminate the effects of HF is to compare between $\varepsilon$ t of straight sections (where no HF exist) and et of critical sections where HF exist.

3.For a given asphalt mix properties, asphalt concrete layer thickness $\left(h_{1}\right)$ has the greater effect to resist the negative influence of HF followed by the base layer modulus $\left(\mathrm{E}_{2}\right)$.

4.More reduction of the effect of HF on the flexible pavement response may achieved by increasing the thickness of base layer $\left(\mathrm{h}_{2}\right)$ followed by enhancing asphalt mix properties to increase its modulus $\left(\mathrm{E}_{1}\right)$.

Finally, it is recommended to conduct field and laboratory studies to determine the practical values of horizontal forces applied at the critical pavement sections, e.g. horizontal curves, intersections, steep upgrades, etc. Further studies should be conducted using practical values of horizontal wheel loads to develop new design charts for critical flexible pavement sections.

\section{References}

[1] Yang, H. H., Pavement Analysis and Design, $2^{\text {nd }}$ Ed., Prince-Hall, Inc, 1993.

[2] Khedr, S., El-Sayed, A., and El-Desouky, A., "Effect of Horizontal Forces on Flexible Pavement Response," Proceedings of the $3^{\text {rd }}$ International Conference on Civil \& Architecture Engineering, March, 1999.

[3] El-Desouky, A., Khedr, S. and El-Sayed, A., "Variation of Flexible Pavement Behavior with Asphalt Concrete Modulus under Various Wheel Loads," Proceedings of the $3^{\text {rd }}$ International Conference on Civil \& Architecture Engineering, March, 1999, Cairo, Egypt. 
[4] El-Desouky, A., El-Sayed, A. and El-Sherief, I., "Effect of Various Tracked Vehicle Loads on Flexible Pavement Life," Proceedings of the $9^{\text {th }}$ International Conference on Applied Mechanics, May, 2000, Cairo, Egypt.

[5] El-Desouky, A., El-Sayed, A. and Fathalla, S., "Studying the Response of Airfield Pavement during Aircraft Ground Operations," Proceedings of the $5^{\text {th }}$ International Conference on Civil \& Architecture Engineering, Nov. 23-25, 2004, Cairo, Egypt.

[6] El-Desouky, A. and El-Shikhy, G., "Studing the Effect of Layer Properties on Flexible Pavement Response at Critical Highway Sections," Proceedings of the $9^{\text {th }}$ Malaysian Road Conference and PIARC Seminar, Nov. 10-12, 2014, Kuala Lumpur, Malaysia.

[7] ANSYS12.1, Engineering Analysis System, Release 12.1, User's Manual, SAS IP, ANSYS University Copy, 2008.

[8] The Asphalt Institute, "Thickness Design - Asphalt Pavements for Highways and Streets", Manual Series No. 1 (MS - 1), September 1981.

[9] Uddin, W., Zhang, D. and Fernandez, F., "Finite Element Simulation of Pavement Discontinuities and Dynamic Load Response", Transportation Research Record, vol. 1448, pp.100-106, 1994. 